\title{
Reproductive Performance, Retention Rate, and Age at the Third Parity According to Growth Rate and Age at First Mating in the Gilts with a Modern Genotype
}

\author{
Jamil Elias Ghiggi Faccin', Fernanda Laskoski', Paulo Emílio Lesskiu', \\ Aline Fernanda Lopes Paschoal', André Luis Mallmann', Mari Lourdes Bernardi' \\ Ana Paula Gonçalves Mellagi', Ivo Wentz' \& Fernando Pandolfo Bortolozzo'
}

\begin{abstract}
Background: Gilts represent the largest category (18-20\%) of female pigs in a breeding herd. Under field conditions, the amplitude of growth rate and age at the first mating of gilts are remarkably higher than the recommendations made by the genetic companies. There are several studies that have considered the management of these animals starting from their introduction to the herd till the mating. It has been noted that the genetic selection constantly promotes evolution that may change certain traits of these animals. However, there is a lack of the studies that evaluate the management strategies suitable for the modern sows. This study, therefore, aimed to evaluate the effect of age and growth rate of gilts at the first mating on productive performance and retention rate until the third farrowing.

Materials, Methods \& Results: The study was performed in a gilt development unit (GDU) with a breeding stock capacity of 1000 females and a goal of 90 gilts mating per week. The groups were retrospectively created according to age $(<210 \mathrm{~d}$ and $\geq 210 \mathrm{~d}$ ) and the growth rate (GR; $<700 \mathrm{~g} / \mathrm{d}$ and $\geq 700 \mathrm{~g} / \mathrm{d}$ ) at the first mating with a $2 \times 2$ factorial design. A real-time ultrasound examination was performed at approximately 28 days after artificial insemination to detect pregnancy. Afterward, the productivity data over three parities of 703 females were collected and analyzed at 28 commercial farms of destination. The analyses were performed using SAS, with individual gilts as the experimental unit. The total number of piglets born and the age at the third parity were analyzed using the PROC MIXED. The number of estrus at breeding, weaning-to-estrus interval and the number of piglets in the previous farrowing were included as covariates in the model of total piglets born. The farrowing rate and retention rate until the third parity were considered as binary responses and analyzed using logistic regression (PROC GLIMMIX). The effects of age, GR, and their interaction were included as fixed effect in all analyses. There was no effect of age and GR and their interaction $(P>0.05)$ on farrowing rate after first, second, and third mating. The total number of piglets born in the three first farrowing and over three parities were not affected $(P>0.05)$ by the age and GR at first mating. The retention rate until the third farrowing of gilts inseminated with more than 210 days of age was approximately $7 \%$ greater than in the gilts mated younger; however, no statistical difference $(P>0.05)$ was detected. An effect of the age at the first mating was observed in the age to reach the third farrowing. Gilts mated with less than 210 and more than 210 days reached the third farrowing, respectively, at $604.5 \pm 1.9$ and $625.1 \pm 2.7$ days of age $(P<0.001)$. Discussion: With a minimum GR of $550 \mathrm{~g} / \mathrm{d}, 180$ days of age, and at least $130 \mathrm{~kg}$ of weight, gilts are eligible to be inseminated without impairing their litter size, farrowing, and retention rate until the third parity. The gilts having modern genotypes can have a high stillbirth rate if bred with an excessive body weight. It is worth to consider that the gilts inseminated with $>700 \mathrm{~g} / \mathrm{d}$ did not present overweight in this study. The reproductive performance expressed by farrowing rate and piglets born and the longevity expressed by the retention rate from the first pregnancy until the third parturition were not impaired by the groups of age and GR in Large White $\times$ Landrace crossbred (Camborough $23^{\circledR}$ ). In addition, gilts inseminated earlier than 210 days but having the minimum required weight resulted in less non-productive days for the breeding herd, which represents an important financial rate to the system.
\end{abstract}

Keywords: sow longevity, productivity, gilt, reproduction, gilt development unit. 


\section{INTRODUCTION}

The reproductive performance of gilts has a fundamental role in the productivity and subsequent profitability of the production systems [2]. It has been observed that swine females need at least three parities to reach a positive net present value to amortize the costs of its production, and four parities to achieve a profit from the investment $[14,19]$. Additionally, the longevity is also an important trait to consider from a productive, economic, and animal welfare perspective in the modern pork production systems [18].

The optimal moment to perform the first mating of gilts depends on the factors such the number of estrus, growth rate (GR), body weight, and age [17]. However, it is difficult to find this optimal moment, since these variables are mutually associated, keep changing, and are, most of the times, achieved at different moments [10]. Another approach is the continuing improvement in the growth performance such that gilts are increasingly heavier but not younger at their first estrus. This has important implications for the strategies on the gilt selection [7]. These aspects contribute to focus on planning, an association of weight and age, longevity and logistic regarding modern genotypes [12].

Under commercial conditions, it has been frequently observed that the demand for replacement gilts can vary according to the need of the farm and the period of the year. Thus in such cases, weekly goals of gilt mating are established on each herd [17].

This work aimed to evaluate the impact of growth rate and age at mating on reproductive performance and on retention until the third parity in Large White $\times$ Landrace crossbred (Camborough $\left.23^{\circledR}\right)^{1}$ gilts.

\section{MATERIALS AND METHODS}

\section{Animals and managements}

This study was conducted in a gilt development unit, located in the Midwest of Santa Catarina state, Brazil. The data such as age, weight, the number of estrus, and growth rate (GR, g/d) from Large White $\times$ Landrace crossbred (Camborough $23^{\circledR}$ ) gilts at first mating were collected.

Groups of 12 gilts were housed in pens with partially slatted floor and in a space allowance of $1.5 \mathrm{~m}^{2}$ per gilt during the development and puberty stimulation phases. All gilts had ad libitum access to water and 2.2 $\mathrm{kg} / \mathrm{d}$ of a corn-soybean diet $(3,204 \mathrm{kcal} \mathrm{ME} / \mathrm{kg}, 14.2 \%$ $\mathrm{CP}$ and $0.64 \%$ digestible lysine).

The onset of puberty stimulation occurred at the next day of their arrival at an average age of 157.6 \pm 4.6 days. A sexual mature boar was introduced twice daily into each pen for $15 \mathrm{~min}$. The puberty attainment was determined as the day, a gilt first exhibited the standing reflex in response to contact with a boar.

Two weeks before the expected breeding, the gilts were transferred to individual crates $(0.55 \times 2.2$ $\mathrm{m})$ for acclimation to the new environment and had $\mathrm{ad}$ libitum access to feed and water. After insemination, the gilts were fed a gestation diet $(2.4 \mathrm{~kg} / \mathrm{d}$, split into two meals of the same amount).

A real-time ultrasound examination was performed at approximately 28 days after the artificial insemination to detect the pregnancy. The pregnant gilts were delivered to 28 sow units at 34 days of gestation. In all units, the pregnant females were kept in individual crates until being transferred to the farrowing room. The management recommendations, as well as, the source and amount of the feed were the same in all farms. Subsequently, the reproductive data such as the farrowing rate in the first three cycles and the age of culling or death, age at the third parity, the total number of piglets born in each parity and over three parities were recorded.

The exclusion criteria for the gilts were the animals receiving hormonal treatment for estrus induction, bleeding during the insemination, and those with locomotor problems, since these factors can influence the response to the factors analyzed. After collecting the data, 703 pregnant gilts were considered eligible and were included in the analysis. During the breeding, two groups based on age ( $<210$ and $\geq 210$ days) and two based on GR ( $\geq 700$ and $<700 \mathrm{~g} / \mathrm{d}$ ) were retrospectively made with a $2 \times 2$ factorial design.

\section{Statistical analysis}

All analyses were performed using the Statistical Analysis System $\left(\mathrm{SAS}^{\circledR} \text { version 9.1.3) }\right)^{2}$ with each individual gilt representing the experimental unit. The total number of piglets born and the age at the third parity were analyzed using the PROC MIXED. The number of estrus at breeding, weaning-to-estrus interval, and the number of piglets in previous farrowing were included as covariates in the model of total piglets born. Farrowing rate and retention rate until the third parity were considered as binary responses and 
analyzed using logistic regression (PROC GLIMMIX). The effects of age, GR, and their interaction were included as fixed effect in all analyses.

\section{RESULTS}

Overall, gilts were inseminated at $204 \pm 0.45$ days of age (180-254 d) with GR of $714 \pm 1.8 \mathrm{~g} / \mathrm{d}$ $(550-892 \mathrm{~g} / \mathrm{d}), 145.6 \pm 0.24 \mathrm{~kg}(130-163 \mathrm{~kg})$ and at $2.1 \pm 0.02$ estrus (2-3 estrus). There were no effects $(P>0.05)$ of age, GR, and their interaction on the farrowing rate in any parity. The farrowing rate at first cycle exceeded $94 \%$ (Table 1) because only gilts with confirmed pregnancy by ultrasonography were sent to the sow herds. The total number of piglets born in each parity and the number of piglets born cumulatively in three parities were not influenced by age, GR, and their interaction $(P>0.05)$.

For retention rate until the third parity, no effect $(P>0.05)$ of age and GR, and their interaction were observed (Table 2). The age at the third parity was influenced by the age at first insemination $(P<0.001)$. Gilts mated younger than 210 days of age reached the third farrowing 20.6 days younger when compared with gilts mated older.

Table 1. Farrowing rate and the total number of piglets born at the first three parities and cumulatively over three parities, according to age (days) and GR (g/day) at the first mating.

\begin{tabular}{|c|c|c|c|c|}
\hline \multirow{2}{*}{ Variable } & \multicolumn{2}{|c|}{ Age $<210$} & \multicolumn{2}{|c|}{ Age $\geq 210$} \\
\hline & $\mathrm{GR}<700$ & $\mathrm{GR} \geq 700$ & $\mathrm{GR}<700$ & $\mathrm{GR} \geq 700$ \\
\hline Number of gilts & 114 & 368 & 160 & 61 \\
\hline Age, days & $204.9 \pm 0.72$ & $196.7 \pm 0.40$ & $218.5 \pm 0.61$ & $213.6 \pm 0.99$ \\
\hline GR, g/day & $679 \pm 2.7$ & $749 \pm 1.5$ & $660 \pm 2.2$ & $721 \pm 3.7$ \\
\hline Farrowing $1(\%) *$ & 97.4 & 94.8 & 96.2 & 95.1 \\
\hline Farrowing $2(\%)$ & 86.0 & 84.6 & 86.9 & 81.5 \\
\hline Farrowing $3(\%)$ & 94.2 & 92.2 & 93.4 & 93.5 \\
\hline Total Born - Parity 1 & $11.1 \pm 0.24$ & $11.2 \pm 0.13$ & $11.6 \pm 0.20$ & $11.0 \pm 0.32$ \\
\hline Total Born - Parity 2 & $11.5 \pm 0.30$ & $11.3 \pm 0.16$ & $11.2 \pm 0.24$ & $11.6 \pm 0.41$ \\
\hline Total Born - Parity 3 & $12.3 \pm 0.32$ & $12.0 \pm 0.17$ & $12.0 \pm 0.25$ & $12.0 \pm 0.43$ \\
\hline Total Born accumulated** & $29.2 \pm 1.00$ & $29.8 \pm 0.56$ & $31.1 \pm 0.85$ & $29.5 \pm 1.37$ \\
\hline
\end{tabular}

Values expressed as LS means \pm standard error except for farrowing 1,2 and 3. No significant differences were observed for any variable $(P>0.05)$; *Farrowing rate of gilts with a previous confirmed pregnancy only; **For total number of piglets born over 3 parities, only sows that reached the 2nd and 3rd farrowing, without any interruption (return to estrus, abortion or failure to farrow) were considered for the analysis. GR= growth rate.

Table 2. Retention rate and age at the third parity according to age (days) and GR (g/day) at the first mating.

\begin{tabular}{|c|c|c|c|c|}
\hline \multirow{2}{*}{ Variable } & \multicolumn{2}{|c|}{ Age $<210$} & \multicolumn{2}{|c|}{ Age $\geq 210$} \\
\hline & $\mathrm{GR}<700$ & $\mathrm{GR} \geq 700$ & $\mathrm{GR}<700$ & $\mathrm{GR} \geq 700$ \\
\hline Number of gilts & 114 & 368 & 160 & 61 \\
\hline Retention rate until $3^{\text {rd }}$ parity ( $\%$ ) & 63.2 & 63.9 & 71.2 & 68.8 \\
\hline Mean $(\%)$ & \multicolumn{2}{|c|}{63.7} & \multicolumn{2}{|c|}{70.6} \\
\hline Age at $3^{\text {rd }}$ parity $(\mathrm{d})^{*}$ & $603.8 \pm 3.5$ & $605.2 \pm 1.9$ & $625.9 \pm 2.7$ & $624.3 \pm 4.7$ \\
\hline Mean $(d) *$ & \multicolumn{2}{|c|}{$604.5 \pm 1.9 \mathrm{a}$} & \multicolumn{2}{|c|}{$625.1 \pm 2.7 b$} \\
\hline
\end{tabular}

\footnotetext{
*Values expressed as LS means \pm standard error. Different letters within the same row are statistically different $(P<0.001)$. GR $=$ growth rate.
} 


\section{DISCUSSION}

In most situations, poor management in breeding herd increases the need for the replacement gilts. Thus the number of replacement gilts can be predefined on the basis of the retention rate and other goals, mating an extra number of gilts increases the number of animals bred without the requirements established by the genetic companies. Additionally, improving sow longevity, herd stability, and maximizing the lifetime performance in a sow herd represent significant challenges to the swine industry [15].

The importance of a proper condition for the insemination of gilts and its impact on lifetime productive performance has already been investigated in other studies. Females with GR $\geq 700 \mathrm{~g} / \mathrm{d}$ had a higher total number of piglets born in the first farrowing [10] but the cumulative production of piglets over three cycles was not influenced by GR. The gilts mated with GR $>770 \mathrm{~g} / \mathrm{d}$ had a larger litter size at the first farrowing but a higher percentage of stillborn piglets compared to the gilts with lower GR [1], evidencing the risk of increased stillbirth rate in overweighed females [5]. It is important to emphasize that in an earlier study [1], the average weight at mating was $160 \mathrm{~kg}$, contrasting with the maximum of $154 \mathrm{~kg}$ reached by the females in the present study, probably explaining why the number of stillborn piglets was not statistically different over three parities (data not shown). It has already been stated that regardless of the age and backfat thickness, the gilts those have already presented estrus and reached $135 \mathrm{~kg}$ are eligible to be inseminated without affecting the number of total piglets born until the third farrowing [20]. Taking this into account, the absence of the effect of age and GR on the total number of piglets born and those born alive in each parity and cumulative in three parities can possibly be explained by the fact that only one gilt weighed less than $135 \mathrm{~kg}$ at the first mating in the present study. In a study performed with a different genotype [11], the mated gilts with less than $139 \mathrm{~kg}$ had smaller litter size at the second parity and even over three parities when compared with the lighter animals. In the present study, even though $59 \%$ of females were mated with GR $<700$ $\mathrm{g} / \mathrm{d}$ and $<210 \mathrm{~d}$ of age, they weighed 130 to $138 \mathrm{~kg}$ and their performance was not impaired. The different female genotype, used in the study of Lesskiu et al. [11], likely accounts for the greater influence of lower weight at mating on litter size, since the recommendation for this genetic line is to inseminate gilts at an older age and with higher weight [4].

The effect of GR on the farrowing rate is less consistent than its effect on the litter size of the first parity. Even with a great variation in GR (397 to 883 $\mathrm{g} / \mathrm{d}$ ) from birth to entry in a breeding herd, the farrowing rate until the third parity was not affected [17]. Kummer et al. [10] also observed that farrowing rate over three parities was not affected by GR at the first mating. These results are similar to the observed in the present study and an appropriate explanation is that both GR and age range and even the genetic line were similar to those studied by Kummer et al. [10].

In a study, 95 farms were categorized into three different levels of productivity (high, medium, and low); those with low productivity were found to breed older gilts, indicating a mismanagement, which could delay the achievement of the required weight to perform the first service [9]. Therefore, using age as a single factor to determine the moment of first mating could be risky, especially when gilts do not reach a minimum weight of $130 \mathrm{~kg}$ [10].

Young females tend to consume lower amount of feed during the lactation phase leading to subsequent higher weight loss [3,6]. A logical consequence of this physiological condition in these females is an inadequate development and oocyte maturation [16], which directly affects the litter size in subsequent farrowing and increases the chance of reproductive failure in the next cycle [13]. In the present study, although the body weight was not recorded at the first farrowing and weaning, some decrease in farrowing rate was expected for primiparous sows but no difference was detected between the four groups.

The retention rate was not affected by the conditions of a female at mating, being in line with other studies [10,11], although a numerical increase of $6.9 \%$ in the retention rate was observed in the gilts mated with $\geq 210$ days. Considering that only females with confirmed pregnancy were sent to the destination farm in this study, the actual retention rate should be reduced by $3-5 \%$, since this was the average loss after the insemination in GDU for that period. In another study, the moment of culling was not associated with GR from birth until the arrival in GDU, indicating that a higher GR seems not to influence the age at the removal of the herd [17]. Indeed, Lesskiu et al. [11] reported 
that the weight at first weaning, GR from mating to farrowing, and the number of piglets born in the first farrowing affected the culling rate rather than the age or weight at first mating.

The gilts mated older tend to be heavier at farrowing, consequently having higher maintenance requirements and greater cost of production during their productive lifetime [8]. In our study, the females inseminated with $<210$ and $>210$ days of age had on average 145 and $147 \mathrm{~kg}$ weight at the first mating, respectively, with an expectation of no difference in the weight at the first farrowing and further maintenance costs. Considering that animals were reared in a specialized unit for gilts management, as prescribed by Lesskiu et al. [11], a good management might have contributed to the high longevity of gilts in both studies. If gilt management is performed in a non-specialized unit, high heterogeneity in practices is expected that might possibly cause a reduction in the reproductive performance. Thus, fewer non-productive days can be obtained if an appropriate management of gilts is performed ensuring a minimum weight at the first mating.

\section{CONCLUSIONS}

Gilts having at least one estrus before mating, minimum $550 \mathrm{~g} / \mathrm{d}$ of GR and $130 \mathrm{~kg}$ weight are eligible to be inseminated with a minimum of 180 days of age without impairing their litter size, farrowing and retention rates until the third parity. Furthermore, a reduction of 20.6 non-productive days can be achieved if insemination is performed before 210 days of age.

\section{MANUFACTURERS}

${ }^{1}$ PIC USA Inc. Hendersonville, TN, USA.

${ }^{2}$ SAS Institute Inc. Cary, NC, USA.

Declaration of interest. The authors report no conflicts of interest. The authors alone are responsible for the content this paper. This study was not supported by any research funding.

\section{REFERENCES}

1 Amaral Filha W., Bernardi M.L., Wentz I. \& Bortolozzo F.P. 2010. Reproductive performance of gilts according to growth rate and backfat thickness at mating. Animal Reproduction Science. 121(1): 139-144.

2 Bortolozzo F.P., Bernardi M.L., Kummer R. \& Wentz I. 2009. Growth, body state and breeding performance in gilts and primiparous sows. In: Control of Pig Reproduction VIII. Nottingham: Nottingham University Press, pp.281-291.

3 Close W.H. \& Cole D.J.A. 2001. Nutrition of sows and boars. Nottingham: Nottingham University Press, 377p.

4 Danbred. 2012. Manejo de fêmeas de reposição. 2.ed. Patos de Minas: Danbred, 46p.

5 Dial G.D., Marsh W.E., Poison D.D. \& Vaillancourt J.P. 1992. Reproductive failure: differential diagnosis. In: Leman A.D., Straw B.E., Mengeling W.L., D'allaire S. \& Taylor D.J. (Eds). Diseases of Swine. 7th edn. Ames: Iowa State University Press, pp.88-137.

6 Eissen J.J., Kanis E. \& Kemp B. 2000. Sow factors affecting voluntary feed intake during lactation. Livestock Production Science. 64(2): 147-165.

7 Foxcroft G. 2015. Potential productivity captured for life. National hog farmer blueprint $n^{o}$. 60. 3p. Available at: <http:// www.nationalhogfarmer.com/reproduction/blueprint-sow-potential- productivity-captured-life>. [Accessed December 2016].

8 Jackson A. 2009. Practical Control of Sow Feed Costs. Advances in Pork Production. 20: 75-80.

9 Kaneko M. \& Koketsu Y. 2012. Gilt development and mating in commercial swine herds with varying reproductive performance. Theriogenology. 77(5): 840-846.

10 Kummer R., Bernardi M.L., Wentz I. \& Bortolozzo F.P. 2006. Reproductive performance of high growth rate gilts inseminated at an early age. Animal Reproduction Science. 96(1): 47-53.

11 Lesskiu P.E., Bernardi M.L., Wentz I. \& Bortolozzo F.P. 2015. Effect of body development from first insemination to first weaning on performance and culling until the third farrowing of Landrace $\times$ Large White swine females. Arquivo Brasileiro de Medicina Veterinária e Zootecnia. 67(2): 465-473.

12 Lesskiu P.E. \& Brandt G. 2010. Novidades no manejo de leitoas. Acta Scientiae Veterinariae. 38(Suppl 1): 105-119.

13 Mellagi A.P.G., Bierhals T., Panzardi A., Gheller N.B., Bernardi M.L., Wentz I. \& Bortolozzo F.P. 2013. Efeito da ordem de parto e da perda de peso durante a lactação no desempenho reprodutivo subsequente de matrizes suínas. Arquivo Brasileiro de Medicina Veterinária e Zootecnia. 65(3): 819-825.

14 Pinilla J.C. \& Lecznieski L. 2010. Parity distribution, management and culling. Manitoba. In: Proceedings of the 24th Manitoba Swine Seminar. vol.24. (Manitoba, Canada). p.113. 
15 Patterson J., Triemert E. \& Gustafson B. 2016. Validation of the use of exogenous gonadotropins (PG600) to increase the efficiency of gilt development programs without affecting lifetime productivity in the breeding herd. Journal of Animal Science. 94(2): 805-815.

16 Quesnel H., Mejia-Guadarrama C. A., Dourmad J. Y., Farmer C. \& Prunier A. 2005. Dietary protein restriction during lactation in primiparous sows with different live weights at farrowing: I. Consequences on sow metabolic status and litter growth. Reproduction Nutrition Development. 45(1): 39-56.

17 Roongsitthichai A., Cheuchuchart P., Chatwijitkul S., Chantarothai O. \& Tummaruk P. 2013. Influence of age at first estrus, body weight, and average daily gain of replacement gilts on their subsequent reproductive performance as sows. Livestock Science. 151(2): 238-245.

18 Serenius T., Stalder K.J. \& Fernando R.L. 2008. Genetic associations of sow longevity with age at first farrowing, number of piglets weaned, and wean to insemination interval in the Finnish Landrace swine population. Journal of Animal Science. 86(12): 3324-3329.

19 Stalder K.J., Lacy R.C., Cross T.L. \& Conatser G.E. 2003. Financial impact of average parity of culled females in a breed-to-wean swine operation using replacement gilt net present value analysis. Journal of Swine Health and Production. 11(2): 69-74.

20 Williams N.H., Patterson J. \& Foxcroft G. 2005. Non-negotiables in gilt development. Advances in Pork Production . 16: $281-289$. 